\title{
Analisis Pola Asuh Orang Tua terhadap Keterlambatan Bicara pada Anak Usia Dini
}

\author{
Nur Hasanah ${ }^{{ }_{1}}$, Sugito $^{2}$ \\ Pendidikan Anak Usia Dini, Universitas Negeri Yogyakarta \\ DOI: $\underline{10.31004 / o b s e s i . v 4 i 2.456}$
}

\begin{abstract}
Abstrak
Faktor utama yang mempengaruhi keterlambatan bicara pada anak ialah pola asuh orang tua. Pola asuh orang tua kurang tepat bagi anak usia dini di masa perkembangannya. Tujuan penelitian ini yaitu untuk menganalisis hubungan pola asuh orang tua terhadap keterlambatan bicara anak. Metode penelitian yang digunakan dalam penelitian ini adalah kajian pustaka. Hasil penelitian menunjukkan bahwa kebanyakan orang tua menerapkan pola asuh permisif dalam mendidik dan mengasuh anak. Pola asuh permisif menyebabkan keterlambatan bicara anak karena kesibukan orang tua, rendahnya tingkat pendidikan orang tua, kurangnya stimulasi, dukungan positif lingkungan dan interaksi, keinginan orang tua agar anak mampu berbahasa asing.
\end{abstract}

Kata Kunci: pola asuh; keterlambatan bicara; anak usia dini.

\begin{abstract}
The main factor influencing speech delay in children is parenting. Parenting patterns are not appropriate for early childhood during their development. The aim of this study was to analyze the pattern of parental relationships with children's speech delays. The research method used in this study is library research. The results showed that parents apply permissive parenting in educating and caring for children. Permissive parenting causes children's speech delays due to busy parents, low levels of parental education, increased stimulation, positive environmental support and interaction, the desire of parents for children to be able.
\end{abstract}

Keywords: parenting; late talking; early childhood.

$\triangle$ Corresponding author:

Email Address : nh55523@gmail.com (Kendari, Sulawesi Tenggara)

Received 1 February 2020, Accepted 25 February 2020, Published 6 March 2020 


\section{PENDAHULUAN}

Pendidikan anak usia dini ialah pendidikan yang berikan kepada anak usia 0-6 tahun. Usia ini merupakan periode kritis dalam menumbuhkembangkan dasar berpikir, berprilaku dan kesejahteraan emosional anak (Bakken, Brown, \& Downing, 2017). Masa ini juga merupakan yang paling mudah dalam menerima stimulasi. Sehingga peran orang tua dan lingkungan sangat dibutuhkan dalam memberikan stimulasi perkembangan anak salah satunya adalah perkembangan bahasa.

Bahasa merupakan suatu sistem atau tanda yang digunakan anak untuk bersosialisasi dan berkomunikasi (Fika, Meilanie, \& Fridani, 2019). Komunikasi dalam berbagai bentuk penyampaian baik secara verbal, non verbal, ditulis maupun diucapkan (M, 2017). Komunikasi tercipta melalui suatu sistem terstruktur yang mencakup bunyi (fonetik), kata-kata atau leksikon (semantik), tata bahasa (sintaksis), dan penggunaan bahasa (semantik) (Foley \& Thompson, 2003; Sanders \& Morawska, 2018). Elemen-elemen ini saling terhubung satu sama lain dalam menciptakan sebuah makna dalam bahasa.

Perkembangan bahasa anak sangatlah mengagumkan karena dalam waktu singkat anak mampu mengusai bahasa yang sangat kompleks. Penelitian mengemukakan bahwa bayi sangatlah peka terhadap bahasa yang diungkapkan oleh lingkungannya, terlihat dari sensitifitas bayi terhadap perubahan fonem yang terjadi bahkan ketika fonem tersebut berubah menjadi bahasa non-pribumi (Morse \& Cangelosi, 2017). Selain itu, menurut (Golinkoff, Can, Soderstrom, \& Hirsh-Pasek, 2015) menyatakan bahwa sebelum bayi belajar bahasa, bayi akan memperhatikan dan membedakan dari suara yang ada di lingkungannya. Perkembangan bahasa akan terus berkembang seiring dengan kematangan anak dan stimulasi yang diberikan oleh lingkungan.

Usia 2,5 tahun sampai 5 tahun adalah usia paling puncak dan cepat dalam perkembangan bahasa dibandingkan dengan anak balita (Joni, 2015). Keterampilan bahasa pada anak dianggap sebagai tolak ukur normalnya berkembangan anak (Sunderajan \& Kanhere, 2019). Kemampuan anak untuk memperoleh kosakata sangat penting dalam mendukung perkembangan bahasa secara menyeluruh. Kosa kata ialah bagian penyusun sintaksis yang kemudian berbentuk percakapan. Percakapan ini mendorong anak untuk mengembangkan kemampuan bercerita kembali tentang kisah pribadi dan kisah fiksi namun dalam bentuk narasi (Lake \& Evangelou, 2019). Dalam hal ini proses anak dalam berbahasa melibatkan beberapa tahapan yaitu mengkode, mengirim informasi dan menguraikan informasi yang dimaksudkan (Sylvestre, Bussières, \& Bouchard, 2016)

Bahasa dibedakan menjadi dua yaitu bahasa ekspresif dan reseptif. Perkembangan bahasa ekspresif dalam penyampaian bahasanya melewati suatu sistem artikulasi yang diungkapkan melalui organ berbicara. Berbicara merupakan ungkapan lisan dan menjadi hal penting bagi seorang anak. Sejalan dengan pendapat tersebut, berbicara merupakan keterampilan dalam berbahasa dan perkembangannya yang didahului melalui kemampuan anak dalam menyimak, dan pada saat itu anak akan juga belajar dalam berbicara dan berujar (Taringan, 2008). Berbicara juga disebut sebagai salah satu bentuk bahasa yang berkaitan dengan artikulasi yang berguna untuk menyampaikan pesan atau informasi yang ada dalam pikiran seorang anak (Maria \& Siringoringo, 2020). Hal ini dikarenakan, dalam berbicara seorang anak bermaksud untuk memberikan informasi, pengetahuan, gagasan, argumentasi dan bahkan pemikiran untuk mempengaruhi pendengar (McLaughlin, 2011; Musfiroh, 2017).

Penggunaan kosa kata dan kecakapan anak dalam berbahasa bergantung pada pengalaman yang didapatkan anak di dalam keluarga dan lingkungan (Kurniasari \& Sunarti, 2019). Keluarga khususnya orang tua memegang peranan yang sangat besar dalam membantu perkembangan berbicara dan bahasa anak yakni melalui cerita, tebak-tebakan, permainan kata, bernyanyi, membaca buku bersama (McLaughlin, 2011). 
Anak pada usia 4 bulan akan membangun rujukan kata baru di memorinya. Kemudian, kosakata tersebut akan berhubungan positif pada ujarannya di usia 30 bulan (Singleton \& Saks, 2015). Hal ini terjadi karena adanya pengaruh dari pola asuh orangtua dan lingkungan yang mendukung perkembangan bicara anak. Perkembangan bicara seorang anak normalnya dimulai melalui tahapan kombinasi cooing, celotehan, babbling, kata pertama dan menggambungkan kata-kata (Berk, L, 2012; McLaughlin, 2011). Seorang anak yang tidak melewati tahapan itu perlu di curigai apakah mengalami keterlambatan bicara atau bahkan masalah serius lainnya.

Secara signifikan anak dikatakan mengalami keterlambatan bicara, apabila ucapan anak di bawah normal untuk anak seusianya seperti membuat banyak kesalahan dalam berbahasa, adanya penambahan atau penghapusan konsonan. Selain itu, pada usia 4-6 tahun anak yang mengalami keterlambatan bicara terlihat saat menurunya kemampuan membaca, tidak mampu untuk mengeja hasil ciptaan nya sendiri, keterampilan verbal dan ejaan anak yang buruk, ketidakmampuan anak untuk mengetahui makna yang terkandung dalam tulisan, adanya masalah perilaku, serta anak mengalami kesulitan dalam berkomunikasi sehingga mempengaruhi perkembangan lainnya seperti perkembangan sosial, emosional, kognitif, psikologis dan akademik anak (Berk, L, 2012; Cantwell \& Baker, 1987; Dodd \& Thompson, 2001; Fitriyani, Sumantri, \& Supena, 2019; Shetty, 2012). Selain itu, anak usia dini mengalami keterlambatan bicara apabila anak mengalami kerancuan bicara pada tahap belajar bahasa (Yuliana \& Zahar, 2017). Kerancuan bicara anak terdiri dari empat bentuk yaitu, 1) Lipsing, yaitu ketika berbicara terdapat pergantian huruf; 2) Slurring, yaitu ketidakjelasan dalam berbicara; 3) Stuttering, yaitu gagap dan keragu-raguan ketika berbicara; 4) Cluttering, yaitu Ketika berbicara sangat cepat dan susah untuk dipahami maksudnya.

Berdasarkan kajian yang telah di lakukan terhadap penelitian terdahulu ditemukan salah satu penyebab anak mengalami keterlambatan berbicara adalah karena pola asuh orang tua yang kurang tepat diterapkan pada anak sehingga berkurang pula pengalaman yang didapatkan anak baik di dalam keluarga maupun di lingkungan.

Pola asuh merupakan strategi orang tua kepada anak yang berhubungan dengan sosialisasi, merawat, mendidik, membimbing, melindungi, pendisiplinan anak dan sebagai proses anak untuk belajar dalam bertingkah laku agar sesuai dengan standar dan harapan sosial (Ma'rifah, Suryantini, \& Mardiyana, 2018; Muin, 2015; Rachmawati \& Nurmawati, 2014). Di indonesia, penerapan program pengasuhan sangatlah beragam. Hal ini berkaitan dengan intervensi, kurikulum, pengaturan orang tua dan dukungan sosial maupun individu (Britto et al., 2017; Chen \& Chan, 2015). Keterampilan orang tua dalam mengasuh anak secara signifikan berdampak besar pada pertumbuhan dan perkembangan bahasa anak di dalam kehidupan (A'yun \& Masykur, 2019; Garcia, Bagner, Pruden, \& Nichols-Lopez, 2015; Mulqiah, Santi, \& Lestari, 2017). Pengalaman negatif yang anak dapatkan di masa kecil akan memberikan tantangan jangka panjang terhadap perkembangan anak selanjutnya (Lomanowska, Boivin, Hertzman, \& Fleming, 2017). Termasuk pengalaman yang anak dapatkan di dalam keluarga atas pengasuhan orang tua.

Orang tua mempunyai andil dalam keterlambatan bicara yang dialami anak. Kebanyakan keterlambatan bicara dialami oleh anak laki-laki, mengasuh anak keterlambatan bicara bukanlah hal yang mudah (Wallace et al., 2015). Berdasarkan permasalahan yang ada, penelitian ini dilakukan untuk mengidentifikasi pola asuh orang tua terhadap keterlambatan bicara pada anak usia dini berdasarkan pada penelitian yang telah dilakukan terdahulu.

\section{METODOLOGI}

Penelitian ini menggunakan metode kajian pustaka. Kajian pustaka digunakan untuk menjawab permasalahan peniltian melalui literatur dan data-data penelitian terdahulu. Dalam penelitian kajian pustaka, literatur dan data-data yang relevan dijadikan sebagai objek utama penelitian, sehingga tidak dibutuhkan lagi riset secara langsung di 
lapangan. Selain itu, 3 alasan mengapa peneliti melakukan penelitian kajian pustaka, yaitu: 1) masalah dalam penelitian hanya dapat dijawab melalui penelitian kepustakaan; 2) kajian pustaka di butuhkan; 3) kajian pustaka dapat di percaya hasilnya dalam menjawab permasalahan penelitian (Pebriana, 2017b). Lebih lanjut Anderson (Pebriana, 2017a) mengungkapkan penelitian kajian pustaka dilakukan dengan maksud untuk meringkas, menganalisis dan menafsirkan teori yang berhubungan dengan penelitian.

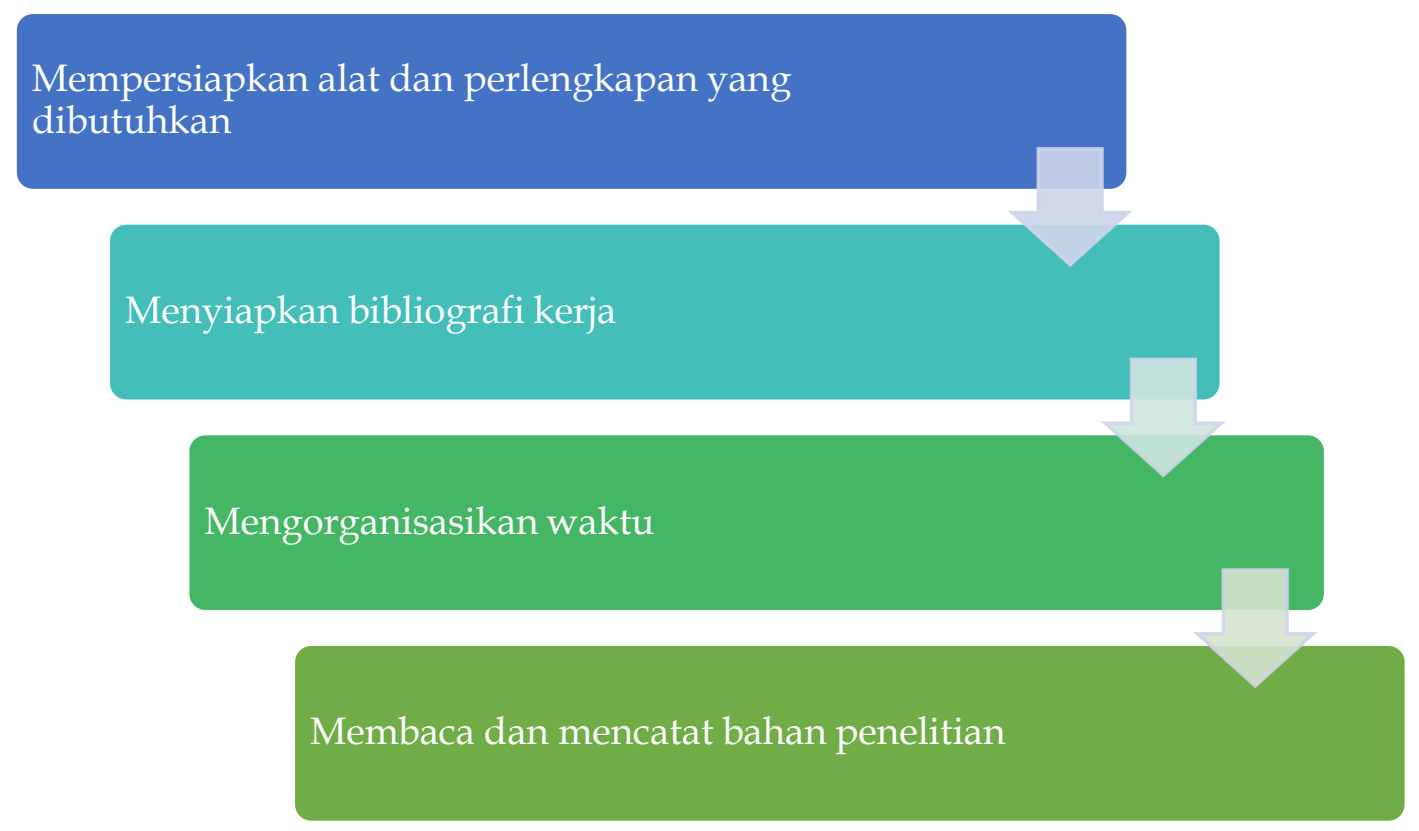

\section{Gambar 1. Langkah-langkah penelitian kajian pustaka}

Terdapat empat langkah dalam penyelidikan literatur yang menjadi pedoman bagi peneliti (Nasution, 2017) antara lain, 1) Mencari literatur; 2) Menilai literatur melalui beberapa kriteria, 3) Memeriksa dan menganalisis isi literatur secara sistematis; 4) Mensintesis isi literatur. Hal tersebut sejalan dengan empat langkah untuk melakukan penelitian studi pustaka (Zed, 2008), antara lain.

\section{HASIL DAN PEMBAHASAN}

Keterlibatan orang tua dalam mengasuh anak memberikan ketertarikan pada peneliti. Ditemukan beberapa pola asuh orang tua yang digunakan dalam kehidupan sehari-hari antara lain pola asuk demokratis, pola asuh otoriter, dan pola asuh permissive. Pola asuh orang tua dibagi menjadi tiga macam (Hurlock, 1999).

\section{Tabel 1. Pola asuh orang tua}

\begin{tabular}{lll}
\hline No. & Macam-macam & \multicolumn{1}{c}{ Keterangan } \\
\hline 1. & Demokratis & $\begin{array}{l}\text { Orang tua memberikan anak kebebasan dalam mengungkapkan } \\
\text { pendapat namun tetap dalam kontrol orang tua. }\end{array}$ \\
2. & Otoriter & $\begin{array}{l}\text { Orang tua melakukan pengasuhan dengan cara membatasi, } \\
\text { memberi hukuman, dan menuntut anak untuk selalu mengikuti } \\
\text { perintah orang tua. }\end{array}$ \\
3. & Permissive & $\begin{array}{l}\text { Orang tua dengan gaya pengasuhan permisif tidak selalu ikut } \\
\text { terlibat dalam kehidupan anak, orang tua memberikan kebebasan } \\
\text { penuh kepada anak dengan menerapkan sedikit batasan. }\end{array}$ \\
\hline
\end{tabular}


Berdasarkan tabel tersebut dan beberapa hasil penelitian yang telah dikaji, maka pola asuh dapat dijelaskan sebagai berikut:

\section{Pola asuh demokratis}

Pola asuh demoktratis memberikan anak kebebasan dalam mengungkapkan pendapatnya, atau bahkan mempercayai keputusan yang diambil oleh anak. Namun, orang tua juga tetap bertugas untuk mengontrol anak dan memberikan batasan mana yang boleh di lakukan oleh anak dan mana yang tidak. Pola asuh ini menciptkan komunikasi dan hubungan yang harmonis antara anak dan orang tua (Juharta, Tjalla, \& Hidayat, 2015). Penelitian (Pinquart, 2017) menyebutkan adanya kehangatan orang tua, kontrol sikap, pemberian otonomi kepada anak, pengasuhan demokratis mampu mengurangi gejala internalisasi pada anak. Selain itu, anak yang diasuh dengan cara ini menjadikan anak lebih percaya diri, baik, mandiri dan mampu untuk mengungkapkan apa yang ia rasakan.

\section{Pola asuh otoriter}

Orang tua otoriter memiliki karakter yang keras, penuntut, kaku, perfeksionis, sulit untuk diajak berkompromi, sering mengatur, dan cenderung menggunakan hukuman fisik ketika anak melakukan kesalahan (Kurnia, 2019). Penelitian yang dilakukan oleh (Juharta et al., 2015) bahwa orang tua melakukan pengasuhan otoritatif dengan cara membatasi, memberi hukuman ketika anak melakukan kesalahan dan selalu menuntut anak untuk selalu mengikuti perintah orang tua. Sehingga, berdampak bagi anak cenderung tidak mampu untuk mengeluarkan pendapatnya, anak mengalami kesulitan dalam bersosialisasi dan berkomunikasi dengan orang lain.

\section{Pola asuh permissive}

Penelitian yang dilakukan (Juharta et al., 2015) menemukan bahwa orang tua dengan pola asuh permisif percaya bahwa cinta dan kasih sayang merupakan kebutuhan bagi anak, sehingga kegiatan mendisiplinkan anak dianggap sebagai sesuatu kontrol yang akan merusak kreatifitas anak. sehingga, orang tua dengan gaya pengasuhan permisif tidak selalu ikut terlibat dalam kehidupan anak, orang tua memberikan kebebasan penuh kepada anak dengan menerapkan sedikit batasan.

Penelitian mengungkapkan bahwa anak yang dibesarkan dengan gaya pengasuhan permisif akan sulit untuk bersosialisai dengan lingkungannya (Juharta et al., 2015). Ini dipengaruhi oleh kurangnya komunikasi dengan orang tua dan karena kurangnya kontrol diri anak dan kecenderungan anak untuk melakukan sesuatu dengan sesuka hatinya tanpa memikirkan lingkungan. Pengasuhan permisif artinya orang tua membebasan anak untuk melakukan apapun yang disenangi hati namun dengan minimnya tingkat disiplin, interaksi dan batasan pada anak (Rohmah, Astikasari, \& Weto, 2018; Wijayaningsih, 2019). Oleh karena itu, pengasuhan permisif ini secara tidak langsung mampu mempengaruhi perkembangan bicara anak usia dini.

\section{Perkembangan Bicara anak}

Berdasarkan hasil penelitian yang dilakukan oleh (Berk, L, 2012) bahwa perkembangan bicara anak normalnya sebagai berikut, ketika anak berusia 2 bulan pencapaian yang telah dapat dilakukan anak ialah berceloteh (cooing dan babling) dan mengeluarkan suara vokal yang menghibur. Pada usia 2 hingga 6 bulan bayi akan mulai mengamati permainan cilukba yang dilakukan oleh pengasuh.

Bayi mulai untuk berceloteh melalui penambahan konsonan dan pengulangan suku kata serta lebih banyak melakukan celotehan yang melibatkan suara dari bahasa lisan di usia 6-7 bulan. Pada usia 8-12 bulan bayi menggunakan isyarat praverbal dan semakin akuran dalam menumbuhkan perhatian bersama dengan pengasuh yang sering kali memberikan label lisan pada apa yang sedang dilihat oleh bayi. 
Bayi yang berusia 12 bulan sudah mampu untuk berceloteh, mengucapkan kata pertama yang mereka tahu seperti mama dan papa, serta meniru dua hingga tiga suku kata. Pada usia 1 hingga 2 tahun, kosa kata anak terus bertambah sekitar 50 hingga 200 kata dan anak juga dapat menggabungkan dua kata. Kemudian pada usia 2 hingga 5 tahun anak, perkembangan bicara sudah sampai tahap menciptakan kata baru berdasarkan kata yang sudah diketahui, memperluas kata melalui metafora, menggunakan ejaan hasil ciptaan dan perkembangan kosa kata anak telah mencapai 10.000 kata.

\section{Keterlambatan bicara}

Anak usia dini yang mengalami keterlambatan bicara terlihat saat perkembangan bicaranya dibawah normal untuk anak seusainya. Selain itu, anak yang mengalami keterlambatan bicara pada usia 2 tahun akan terus menghasilkan bicara yang lebih buruk dibandingkan dengan anak yang tanpa riwayat keterlambatan bicara diusia 4-5 tahun (Neam, Hodges, \& Munro, 2019). Hasil penelitian yang telah dilakukan bahwa keterlambatan bicara pada anak terlihat pada saat terdapat kerancuan bicara anak. Kerancuan bicara menunjukan bahwa ada empat bentuk kerancuan bicara pada anak usia dini (Yuliana \& Zahar, 2017), yakni,

\section{Tabel 2. Bentuk Kerancuan bicara}

\begin{tabular}{|c|c|c|c|c|}
\hline No. & Bentuk & Kata & Kata Rancu & Keterangan \\
\hline \multirow[t]{4}{*}{1.} & Lipsing & Disitu & Dicitu & $/ \mathrm{s} / \mathrm{menjadi} / \mathrm{c} /$ \\
\hline & & Harimau & Halimau & $/ r /$ menjadi $/ l$ \\
\hline & & Robot & Kobok & $\mid r /, / t /$ menjadi $/ k /, / k$ \\
\hline & & Cowok & Kowok & $/ c /$ menjadi $/ k /$ \\
\hline \multirow[t]{2}{*}{2.} & Sluring & Helikopter & Kopter & $\begin{array}{l}\mathrm{h} /, / \mathrm{e} /, \mathrm{l} / \mathrm{d} \text { dan } / \mathrm{i} / \mathrm{m} \text { mengalami } \\
\text { ketidakjelasan pengucapan }\end{array}$ \\
\hline & & Matahari & Tahali & Ketidakjelasan pada huruf $/ \mathrm{m} /$ dan $/ \mathrm{a} /$ \\
\hline 3. & Stuttering & - & - & - \\
\hline 4. & Chuttering & $\begin{array}{l}\text { Motor balap } \\
\text { bapak polisi }\end{array}$ & $\begin{array}{l}\text { Motoy bayap } \\
\text { bapak cici }\end{array}$ & $\begin{array}{l}/ r / \text { menjadi } / y /, / / \text { menjadi } / y /, \\
\text { Penghilangan huruf } / p / \text { dan } / o / \\
M / \text { menjadi } / c /, / s / \text { menjadi } / c / .\end{array}$ \\
\hline
\end{tabular}

Berdasarkan tabel di atas, keterlambatan bicara dalam bentuk kerancuan bicara memiliki banyak bentuk. Anak sebagian besar menghabiskan masa kecil bersama orang tua. Sejalan dengan temuan penelitian (Tirtawati, Suryani, \& Adriani, 2016)bahwa orang tua menjadi tempat pertama anak belajar memperhatikan keinginan diri sendiri maupun orang lain, selain itu anak belajar untuk bekerja sama, sehingga melalui proses ini dapat memberikan pengalaman anak dalam berinteraksi yang akan menentukan perilaku anak kepada orang lain.

Oleh sebab itu, keterlambatan bicara yang dialami anak berkaitan dengan perlakuan atau pola asuh yang diberikan oleh orang tua kepada anak. Karena pada hakikatnya, orang tua memiliki peran yang penting dalam mendukung perkembangan bicara anak sejak dini (Matondang, 2019). Namun, ketika anak mengalami keterlambatan bicara dapat dipengaruhi karena kurangnya pengalaman yang didapatkan anak ketika dalam dalam pengasuhan orang tua.

Hasil penelitian menunjukkan bahwa kebanyakan orang tua menerapkan pola asuh permisif untuk mendidik yang didasari atas rasa kasihan yang berlebihan terhadap anak. Salah satu penelitian yang telah dilakukan menemukan bahwa pola asuh yang digunakan orang tua pada anak dengan keterlambatan bicara cenderung menggunakan model pengasuhan permisif. Sehingga, pola asuh permisif memiliki andil yang besar dalam menyebabkan keterlambatan bicara anak. (Rohmah et al., 2018). 


\section{Keterkaitan antara pola asuh orang tua dengan keterlambatan bicara anak}

Berdasarkan identifikasi yang telah dilakukan terhadap pola asuh orang tua dan keterlambatan bicara anak ditemukan bahwa keterlambatan bicara pada anak diidentifikasi memiliki keterkaitan dengan pola asuh permisif yang diterapkan orang tua. Berikut adalah beberapa keterkaitan dalam pola asuh permisif yang menyebabkan keterlambatan bicara pada anak.

Tabel 2. Penyebab keterlambatan bicara anak

\begin{tabular}{|c|c|}
\hline Pola asuh & Penyebab \\
\hline Pola asuh permisif dengan & Kesibukan orang tua \\
\hline keterlambatan bicara anak & $\begin{array}{l}\text { Rendahnya tingkat pendidikan orang tua } \\
\text { Kurangnya stimulasi, dukungan positif dan interaksi } \\
\text { Keinginan orang tua agar anak mampu berbahasa asing }\end{array}$ \\
\hline
\end{tabular}

Berdasarkan tabel tersebut maka dapat dijelaskan secara rinci bahwa penyebab keterlambatan bicara. Pertama, kesibukan orang tua yang menyebabkan kurangnya perhatian dan keterlibatan orang tua terhadap perkembangan bicara anak. Padahal orang tua memiliki peranan yang sangat penting dalam perkembangan anak karena orang tua menjadi orang pertama tempat anak dalam berkomunikasi. Kedua, rendahnya tingkat pendidikan orang tua menyebabkan kurangnya pengetahuan untuk memfasilitasi dan menstimulasi perkembangan bicara anak.

Penelitian yng dilakukan oleh (Hartanto, Selina, H, \& Fitra, 2016) menemukan bahwa pendidikan seorang ibu yang rendah memiliki kemungkinan besar untuk anak mengalami keterlambatan bicara dikarenakan kurangnya stimulasi yang diperoleh anak di lingkungan terdekat yaitu orang tua. Orang tua juga pada hakikatnya mempunyai peran sebagai guru bahasa pertama anak dan memiliki kesempatan yang tepat dalam memfasilitasi perkembangan bahasa anak (Siregar \& Hazizah, 2019; Stoner, Meadan, \& Angell, 2013). Hal ini juga terkait dengan penelitian, bahwa orang tua yang mengikuti pelatihan menjadi orang tua akan menunjukkan peningkatan keterampilan dalam pengasuhan dan pengetahuan akan perkembangan anak dibandingkan dengan orang tua yang sama sekali tidak pernah mengikuti pelatihan (Munger, Seeley, Mender, Schroeder, \& Gau, 2019). Ketiga, Kurangnya stimulasi, dukungan positif lingkungan dan interaksi antara anak dan orang tua di masa perkembangan sehingga menyebabkan keterlambatan bicara (Fitriyani et al., 2019). Seorang anak dengan keterlambatan bicara menggunakan kata-kata atau frasa untuk mengungkapkan idenya akan tetapi sulit untuk dimengerti oleh orang lain. Sehingga, orang sekitar anak akan cenderung menghindari percakapan dengan anak.

Selain itu, orang tua juga kurangnya ajakan orang tua untuk berkomunikasi dan berbicara dengan anak (Norcholifah \& Oktavia, 2019). Keempat, keinginan orang tua agar anak mampu berbahasa asing. Oleh karena itu, orang tua berkomunikasi dengan anak menggunakan dua bahasa, seperti bahasa indonesia dan bahasa inggris. Sehingga, penerapan bilingualism di lingkungan keluarga yang membingungkan bagi anak (Shetty, 2012). Sejalan dengan pendapat (Norcholifah \& Oktavia, 2019) bahwa dengan adanya penggunaan bahasa asing di lingkungan keluarga dapat memperlambat anak dalam belajar bahasa ibunya.

\section{SIMPULAN}

Anak di katakan mengalami keterlambatan bicara saat perkembangan bicara anak tidak sesuai dengan anak seusianya. Hal ini dipengaruhi oleh pola asuh permisif yang diterapkan orang tua. Pola asuh permisif ialah pola asuh orang tua dalam mengasuh dan mendidik anak dengan cara membebaskan anak melakukan segala sesuatu sesuai keinginan anak tanpa adanya batasan. Pola asuh ini memiliki andil yang sangat besar dalam 
menyebabkan keterlambatan bicara pada anak usia dini, karena 1) kesibukan orang tua; 2) rendahnya tingkat pendidikan orang tua; 3) kurangnya stimulasi, dukungan positif lingkungan dan interaksi; 4) keinginan orang tua agar anak mampu berbahasa asing. Sehingga mengurangi pengalaman pengetahuan dan berbicara anak di lingkungan keluarga.

\section{UCAPAN TERIMAKASIH}

Ucapan terima kasih diucapkan kepada civitas Akademika Universitas Negeri Yogyakarta dan semua pihak yang telah membantu dalam proses pembuatan artikel ini.

\section{DAFTAR PUSTAKA}

A'yun, W. Q. N., \& Masykur, A. M. (2019). the Relationship Between the Perception of Authoritarian Parenting With Bullying Intentions in Psychology Students of 2018 Diponegoro University. The Relationship Between the Perception of Authoritarian Parenting With Bullying Intentions in Psychology Students of 2018 Diponegoro University, 7(4), 80-84.

Bakken, L., Brown, N., \& Downing, B. (2017). Early Childhood Education: The Long-Term Benefits. Journal of Research in Childhood Education. https:// doi.org/10.1080/02568543.2016.1273285

Berk, L, E. (2012). development through the lifespan (kelima). yogyakarta: pustaka pelajar.

Britto, P. R., Lye, S. J., Proulx, K., Yousafzai, A. K., Matthews, S. G., Vaivada, T., ... Bhutta, Z. A. (2017). Nurturing care: promoting early childhood development. The Lancet, 389(10064), 91-102. https:// doi.org/10.1016/S0140-6736(16)31390-3

Cantwell, D. P., \& Baker, L. (1987). Prevalence and type of psychiatric disorder and developmental disorders in three speech and language groups. Journal of Communication Disorders. https:// doi.org/10.1016/0021-9924(87)90006-2

Chen, M., \& Chan, K. L. (2015). Effects of Parenting Programs on Child Maltreatment Prevention: A Meta-Analysis. Trauma, Violence, and Abuse, 17(1), 88-104. https:// doi.org/10.1177/1524838014566718

Dodd, B., \& Thompson, L. (2001). Speech disorder in children with Down's syndrome. Journal of Intellectual Disability Research. https://doi.org/10.1046/j.13652788.2001.00327.x

Fika, Y., Meilanie, S. M., \& Fridani, L. (2019). Peningkatan Kemampuan Bicara Anak melalui Bermain Peran Berbasis Budaya. Jurnal Obsesi : Jurnal Pendidikan Anak Usia Dini, 4(1), 50. https://doi.org/10.31004/obsesi.v4i1.229

Fitriyani, F., Sumantri, M. S., \& Supena, A. (2019). Language development and social emotions in children with speech delay: case study of 9 year olds in elementary school. Jurnal Konseling Dan Pendidikan. https:// doi.org/10.29210/130600

Foley, J., \& Thompson, L. (2003). language learning. new york: routledge.

Garcia, D., Bagner, D. M., Pruden, S. M., \& Nichols-Lopez, K. (2015). Language Production in Children With and At Risk for Delay: Mediating Role of Parenting Skills. Journal of Clinical Child and Adolescent Psychology, 44(5), 814-825. https:/ / doi.org/10.1080/15374416.2014.900718

Golinkoff, R. M., Can, D. D., Soderstrom, M., \& Hirsh-Pasek, K. (2015). (Baby)Talk to Me: The Social Context of Infant-Directed Speech and Its Effects on Early Language Acquisition. Current Directions in Psychological Science. https:/ / doi.org/10.1177/0963721415595345

Hartanto, F., Selina, H., H, Z., \& Fitra, S. (2016). Pengaruh Perkembangan Bahasa Terhadap Perkembangan Kognitif Anak Usia 1-3 Tahun. Sari Pediatri, 12(6), 386. https:// doi.org/10.14238/sp12.6.2011.386-90

Hurlock, E. B. (1999). Hurlock, E.B. 1999. Chlid Development Jilid II, terjemahan, Jakarta: Erlangga (II; Tjandrasa, ed.). Jakarta: Erlangga. 
Joni. (2015). Hubungan pola asuh orang tua terhadap perkembangan bahasa anak prasekolah (3-5 tahun) di PAUD Al-Hasanah Tahun 2014. PAUD Tambusai, 1(1), $42-$ 48.

Juharta, Y. nur fatimah, Tjalla, A., \& Hidayat, dede rahmat. (2015). Belajar Dilihat Dari Pola Asuh Authoritative , Authoritarian Dan Permisif. Insight Jurnal, 4(1), 1-8. https://doi.org/10.21009/INSIGHT.041.18

Kurniasari, L., \& Sunarti, S. (2019). early detection of speech delay and family factors. Journal of Public Health in Africa, 10(s1), 152-153. https://doi.org/10.4081/jphia.2019.1212

Lake, G., \& Evangelou, M. (2019). Let's Talk! An interactive intervention to support children's language development. European Early Childhood Education Research Journal, 27(2), 221-240. https:// doi.org/10.1080/1350293X.2019.1579549

Lomanowska, A. M., Boivin, M., Hertzman, C., \& Fleming, A. S. (2017). Parenting begets parenting: A neurobiological perspective on early adversity and the transmission of parenting styles across generations. Neuroscience, 342, 120-139. https:/ / doi.org/10.1016/j.neuroscience.2015.09.029

M, S. (2017). The Impact of using Gadgets on Children. Journal of Depression and Anxiety. https://doi.org/10.4172/2167-1044.1000296

Ma'rifah, A., Suryantini, N. P., \& Mardiyana, R. (2018). STRATEGI KOPING ORANG TUA TERHADAP ANAK AUTIS DAN POLA ASUH ORANG TUA. Journal of Health Sciences, 11(2), 196-204.

Maria, D., \& Siringoringo, L. (2020). Hubungan Pendidikan Paud Dengan Perkembangan Bicara Dan Bahasa Pada Anak Usia 36-60 Bulan Di Paud Kasih Ibu Jakarta Utara. 1(1), 27-34.

Matondang, C. E. H. (2019). analisis gangguan berbicara cadel. Jurnal Pendidikan Bahasa Dan Sastra Indonesia, 3(2), 49-59.

McLaughlin, M. R. (2011). Speech and language delay in children. American Family Physician, 83(10), 1183-1188.

Morse, A. F., \& Cangelosi, A. (2017). Why Are There Developmental Stages in Language Learning? A Developmental Robotics Model of Language Development. Cognitive Science, 41, 32-51. https:// doi.org/10.1111/cogs.12390

Muin, S. (2015). Peran Pola Asuh Permisif, Iklim Sekolah, dan Motivasi Berprestasi Terhadap Perilaku Membolos Siswa. PSIKOPEDAGOGIA Jurnal Bimbingan Dan Konseling, 4(2), 93. https:// doi.org/10.12928/psikopedagogia.v4i2.4477

Mulqiah, Z., Santi, E., \& Lestari, D. R. (2017). Pola Asuh Orang Tua Dengan Perkembangan Bahasa Anak Prasekolah (Usia 3-6 Tahun). Dunia Keperawatan, 5(1), 61. https:// doi.org/10.20527/dk.v5i1.3643

Munger, K., Seeley, J., Mender, L., Schroeder, S., \& Gau, J. (2019). Effect of Make Parenting a Pleasure on Parenting Skills and Parental Depression. Child \& Family Behavior Therapy, 42(1), 1-19. https:/ / doi.org/10.1080/00168890.2019.1689915

Musfiroh, T. (2017). Psikolinguistik edukasional: psikolinguistik untuk pendidikan bahasa (kedua). yogyakarta: tiara wacana.

Nasution, M. K. M. (2017). Penelaahan literatur. Sumatera utara.

Neam, S. Y., Hodges, R., \& Munro, N. (2019). Speech production abilities of 4- to 5-year-old children with and without a history of late talking: The tricky tyrannosaurus Sze Yuen Neam, Elise Baker, Rosemary Hodges \& Natalie Munro. International Journal of Speech-Language Pathology, 1-12. https://doi.org/10.1080/17549507.2019.1638968

Norcholifah, A., \& Oktavia, W. (2019). keterlambatan bicara pada anak usia 4 tahun. KLAUSA, 3(2), 79-88. https:// doi.org/10.33479/klausa.v3i2.203

Pebriana, P. H. (2017a). Analisis penggunaan gadget terhadap kemampuan interaksi sosial. Jurnal Obsesi: Jurnal Pendidikan Anak Usia Dini, 1(1), 8. https://doi.org/10.31004/obsesi.v1i1.26

Pebriana, P. H. (2017b). Jurnal Obsesi: Jurnal Pendidikan Anak Usia Dini Analisis Penggunaan Gadget terhadap Kemampuan Interaksi Sosial. Jurnal Pendidikan Anak 
Usia Dini, 1(1), 8. https://doi.org/10.31004/obsesi.v1i1.26

Pinquart, M. (2017). Associations of Parenting Dimensions and Styles with Internalizing Symptoms in Children and Adolescents: A Meta-Analysis. Marriage and Family Review, 53(7), 613-640. https:/ / doi.org/10.1080/01494929.2016.1247761

Rachmawati, A., \& Nurmawati, T. (2014). The Correlation Between Parenting and Emotional Intelligence Of School Age Children. Jurnal Ners Dan Kebidanan (Journal of Ners and Midwifery), 1(1), 007-012. https:/ / doi.org/10.26699/jnk.v1i1.art.p007-012

Rohmah, M., Astikasari, nita dewi, \& Weto, iriyanti. (2018). Analisis Pola Asuh Orang Tua Dengan Keterlambatan Bicara Pada Anak Usia 3-5 Tahun. OKSITOSIN : Jurnal Ilmiah Kebidanan, 5(1), 32-42. https://doi.org/10.35316/oksitosin.v5i1.358

Sanders, M. R., \& Morawska, A. (2018). Handbook of Parenting and Child Development Across the Lifespan. In Handbook of Parenting and Child Development Across the Lifespan. https:/ / doi.org/10.1007/978-3-319-94598-9

Shetty, P. (2012). Speech and language delay in children: A review and the role of a pediatric dentist. Journal of Indian Society of Pedodontics and Preventive Dentistry, 30(2), 103-108. https://doi.org/10.4103/0970-4388.99979

Singleton, N. C., \& Saks, J. (2015). Co-Speech Gesture Input as a Support for Language Learning in Children With and Without Early Language Delay. Perspectives on Language Learning and Education, 22(2), 61. https:/ / doi.org/10.1044/lle22.2.61

Siregar, A. O., \& Hazizah, N. (2019). Studi Kasus Keterlambatan Bicara Anak Usia 6 Tahun di Taman Kanak-Kanak. Aulad: Journal on Early Childhood, 2(2), 22-27. https:// doi.org/10.31004/aulad.v2i2.31

Stoner, J., Meadan, H., \& Angell, M. (2013). A Model for Coaching Parents to Implement Teaching Strategies With Their Young Children With Language Delay or Developmental Disabilities. Perspectives on Language Learning and Education, 20(3), 113. https:/ / doi.org/10.1044/lle20.3.112

Sunderajan, T., \& Kanhere, sujata v. (2019). Speech and language delay in children: Prevalence and risk factors. Journal of Family Medicine and Primary Care, 8(5), 16421646. https://doi.org/10.4103/jfmpc.jfmpc_162_19

Sylvestre, A., Bussières, È. L., \& Bouchard, C. (2016). Language Problems Among Abused and Neglected Children: A Meta-Analytic Review. Child Maltreatment, 21(1), 47-58. https:/ / doi.org/10.1177/1077559515616703

Taringan, H. G. (2008). Menyimak Sebagai Suatu Keterampilan Berbahasa. Bandung: Angkasa.

Tirtawati, D., Suryani, N., \& Adriani, R. benya. (2016). the relationship between child nurturing pattern, family support, and language competence in children aged 5-6 yeras with auditory disorder. Journal of Maternal and Child Health, 1(3), 188-194. https:// doi.org/10.26911/thejmch.2016.01.03.06

Wallace, I. F., Berkman, N. D., Watson, L. R., Coyne-Beasley, T., Wood, C. T., Cullen, K., \& Lohr, K. N. (2015). Screening for speech and language delay in children 5 years old and younger: A systematic review. Pediatrics, 136(2), e448-e462. https:/ / doi.org/10.1542/peds.2014-3889

Wijayaningsih, L. (2019). Peran Pola Asuh Orang Tua dalam Meningkatkan Kemampuan Bicara Anak Speech Delay (Studi Kasus Di Homeschooling Bawen Jawa Tengah). Satya Widya. https:/ / doi.org/10.24246/j.sw.2018.v34.i2.p151-159

Yuliana, \& Zahar, E. (2017). analisis bentuk-bentuk kerancuan berbicara pada anak usia 3-5 tahun. AKSARA, 1(1), 52-62.

Zed, M. (2008). Metode penelitian kepustakaan (1st ed.). Jakarta: Yayasan Obor indonesia. 